\title{
Aplikasi Sistem Pakar Berbasis Instant Messenger Untuk Diagnosa Awal Penyakit Ginjal
}

\author{
Wahyu Rizki Arifianto ${ }^{1}$, I Made Arsa Suyadnya ${ }^{2,}$, I Made Sudarma ${ }^{3}$ \\ Program Studi Teknik Elektro, Fakultas Teknik, Universitas Udayana \\ Kampus Bukit Jimbaran, Bali, tlp. 0361703315 \\ Email. Arif.ppf@gmail.com ${ }^{1}$, arsa.suyadnya@unud.ac.id ${ }^{2}, \underline{\text { msudarma@unud.ac.id }}^{3}$
}

\begin{abstract}
Abstrak
Di Indonesia angka kematian para penderita penyakit ginjal semakin meningkat. Hal ini dikarenakan salah satunya karena kurangnya pengetahuan tentang gejala awal penyakit ginjal. Ginjal adalah organ penting dalam tubuh, dimana ginjal berperan sebagai alat filtrasi yang berfungsi untuk mengeluarkan kelebihan garam, air, dan asam. Pemanfaatan teknologi informasi dapat menjadi salah satu solusi untuk mengatasi permasalahan tersebut. Dengan membangun aplikasi sistem pakar berbasis instant messenger untuk diagnosa awal penyakit ginjal, diharapkan dapat dilakukan proses diagnosa awal lebih cepat dan dapat menjangkau lebih banyak orang yang ingin mengetahui permasalahan penyakit ginjalnya. Metode sistem yang digunakan dalam penelitian ini adalah forward chaining berbasis multiplatform dalam aplikasi instant messaging Telegram. Aplikasi ini dapat menampilkan hasil diagnosa dengan cepat dan tepat berdasarkan gejala-gejala yang ditanyakan oleh sistem. Berdasarkan hasil pengujian menggunakan metode black box, aplikasi memiliki fungsi-fungsi yang sesuai dengan rancangan sistem, dapat berjalan sesuai dengan perintah, dan telah dinyatakan berhasil. Selain itu berdasarkan hasil pengujian system usabilty scale (SUS), didapatkan skor 78 yang berarti keseluruhan fungsionalitas telah berfungsi dengan baik aplikasi ini dapat berjalan dengan baik pada Telegram Messaging.
\end{abstract}

Kata Kunci : Sistem pakar, penyakit ginjal, bot, instant messaging, forward chaining.

\begin{abstract}
In Indonesia, the number of people who dead from suffered kidney disease has increasing. It's happens because many people has less knowledge about the early symptoms of this disease. Kidney is one of the important organ in human body, which's it performs to filtrating excess salt, water, and acid. Information technology utilization could be a great solution for this case. Build an expert system application based on instant messenger for early diagnose check of kidney disease is expect to do the initial diagnose process to be faster and could engage more people who curious about this disease. The system method that was used in this research is forward chaining method who based on multiplatforms using Telegram instant messanger application. This application could solves the problem which is it application can displaying the diagnosis result quickly and accurately based on the symptoms that will be asked by the system. In black box testing, this application has functions that have been successful. And based on the results of usabilty scale system testing (SUS), obtained a score of 78 which means this application can run well on Telegram Messaging.
\end{abstract}

Keywords: Expert system, kidney disease, bot, instant messaging, forward chaining.

\section{PENDAHULUAN}

Berdasarkan data tahun 2013, angka kematian para penderita penyakit ginjal yang semakin meningkat, dikarenakan kurangnya pengetahuan tentang gejala awal penyakit ginjal [1]. Ginjal adalah organ penting dalam tubuh, karena ginjal berperan sebagai alat filtrasi yang berfungsi untuk mengeluarkan kelebihan garam, air, dan asam.

Dengan mengimplementasikan sistem pakar ke dalam komputer, proses diagnosa awal dapat meningkatkan keakurasian, kecepatan, dan dapat diakses kapan pun [2]. Instant messenger merupakan salah satu aplikasi multiplaform yang dapat mengimplementasikan kemampuan komputasi didalamnya. Salah satu contoh penerapannya yaitu oleh Nur pada tahun 2016 menerapkan sebuah sistem rancang bangun social services dan custom tools. Sistem ini memanfaatkan Telegram bot pada Telegram messenger untuk memenuhi kebutuhan sarana informasi dan pendidikan yang memadai [3]. Selain itu 
Chatbot terutama Telegram Bot juga dapat menerapkan sistem pakar di dalamnya.

Pemanfaatan sistem pakar sebagai media untuk mendiagnosa penyakit telah banyak dilakukan, diantaranya Kurniawan pada tahun 2011 telah membangun sistem pakar berbasis web untuk diagnosa penyakit gigi dan mulut dalam program CLIPS [4]. Pada tahun 2011, Kusuma mengembangkan penelitian tersebut yang menghasilkan sistem pakar dengan 18 diagnosa penyakit mulut dan 40 gejala yang menyertainya dengan metode depth first search[5]. Kelemahan penelitianpenelitian tersebut terletak pada basis sistem yang dibuat yaitu menggunakan basis desktop dan web yang membuat sistem hanya dapat diakses oleh masing-masing pengguna platform.

Dengan penjabaran di atas maka mendorong dilakukannya penelitian untuk membangun "Aplikasi Sistem Pakar Berbasis Instant Messenger dalam Aplikasi Telegram Messeger untuk Diagnosa Awal Penyakit Ginjal". Aplikasi ini menjadi media diagnosa awal penyakit ginjal yang lebih cepat dan dapat dijangkau lebih banyak pengguna.

\section{KAJIAN PUSTAKA}

\subsection{Penyakit Ginjal}

Ginjal adalah salah satu organ tubuh manusia yang sangat cukup vital. Hal itu diakibatkan oleh pentingnya organ vital ini terhadap proses perkemihan (ginjal - ureter kandung kemih - uretra). Penyakit ini dapat meningkatkan kemungkinan kematian bagi penderitanya. Karena pengidap penyakit ginjal menjadi awal penyakit yang lebih beresiko (penyakit jantung). Penurunan fungsi organ ginjal hingga tidak mampu bekerja secara normal sebagaimana fungsinya dalam hal penyaringan pembuangan elektrolit tubuh serta menjaga keseimbangan cairan dan zat kimia tubuh adalah tanda seseorang mengidap penyakit ginjal [6].

\subsubsection{Jenis-Jenis Penyakit Ginjal}

Berikut ini adalah jenis-jenis penyakit ginjal yang digunakan dalam penelitian ini, yaitu [7] :

a. Infeksi Saluran Kemih. Terdapat dua jenis Infeksi saluran kemih yaitu infeksi bagian bawah dan bagian atas. Infeksi bakteri pada piala ginjal, tubulus, dan jaringan interstisial dari ginjal merupakan penyakit bagian atas. Sedangkan bagian bawah karna terjadinya infeksi dari bagian uretra. b. Batu Ginjal. Batu ginjal merupakan gumpalan padat yang merupai kerikil pada ginjal. Jenis batu ginjal yang paling umum ditemui yaitu batu kalsium.

c. Kanker Ginjal. Kanker ginjal adalah kelainan yang diakubatkan karena infeksi atau lingkungan sekitar ginjal yang asam yang.

d. Gagal Ginjal Akut. Gagal ginjal merupakan penurunan fungsi ginjal secara drastic dan mendadak.

e. Gagal Ginjal Kronik. Gagal ginjal kronik dikarenakan oleh rusaknya nefron yang tidak dapat sembuh kembali.

f. Sindrom Nefrotik. Sindrom nefrotik (SN) merupakan keadaan terdapatnya proteinuria masif, hypoalbuminemia, edema, dan disertai hiperkolesterolemia [8].

g. Penyakit Ginjal Polikistik. Ketika terdapat terdapat banyak kista di dalam ginjal merupakaan tanda penyakit ginjal polikistik. Kista-kista tersebut biasanya terjadi karena kelainan bawaan.

\subsection{Sistem Pakar (Expert System)}

Berdasarkan pendapat Durkin, Ignizo, dan Giarritano, terdapat beberapa definisi sistem pakar, yaitu [9]:

a. Sistem atau sebuah program komputer yang dirancang untuk memodelkan dan menyelesaikan masalah, layaknya peranan pakar di bidang ilmunyanya adalah definisi sistem pakar.

b. Sistem pakar dikembangkan untuk membantu pengguna komputer agar dapat memahami pengetahuan, sekalipun pengguna tidak memiliki kemampuan ahli tersebut.

c. Sistem pakar dikembangkan yaitu dengan cara mengadaptasi pola pikir dan pengetahuan manusia (pakar), yang berguna untuk solusi untuk membantu penggunanya layaknya dibantu oleh pakar.

\subsection{Metode Forward Chaining (Runut Maju) \\ Forward Chaining adalah sekumpulan} aturan yang diawali oleh kondisi dan menghasilkan aksi. Metode ini diawali dengan menyesuaikan data dan kebutuhan, hasil akan ditemukan hingga proses yang dilakukan memenuhi tujuan. Ilustrasi metode ini yaitu jika diperoleh konklusi dari daftar konklusi yang ada berdasarkan premis-premis dalam aturan dan fakta yang diberikan oleh pengguna[10]. 


\subsection{Knowledge Base (Basis Pengetahuan)}

Basis pengetahuan adalah informasi atau pengetahuan yang didapat dari pakar yang adiadaptasi ke dalam sistem komputer menggunakan metode tertentu. Metode tersebut merupakan cara untuk menulis pengetahuan pakar agar mudah diolah sistem komputer. Selama berkomunikasi akan dilakukan pencocokan oleh mesin terdahadap fakta yang dimasukkan oleh user untuk diambil keputusan dengan pengetahuan yang terdapat dalam basis pengetahuan[10].

\subsection{Instant Messenger}

Instant messenger (IM) merupakan jenis layanan komunikasi yang digunakan untuk melakukan percakapan (chat) privat secara real time melalui saluran internet. Umumnya IM ini berupa pesan teks, suara, ataupun video[10].

Telegram merupakan salah satu instant messaging yang cukup populer. Dalam perkembangannya, muncul salah satu fitur yang dapat dimanfaatkan sebagai media pengembangan sistem pakar, yaitu Telegram Bot. Bot dapat dirancang berinteraksi dengan pengguna, yaitu dengan mengirim pesan, melakukan percakapan, dan sebagainya[10].

Terdapat cara untuk mengembangkan Telegram Bot yaitu menulis bot secara manual menggunakan bahasa pemrograman yang pengembang kuasai, dan menggunakan tag (kata kunci non hierarki yang mewakili suatu instruksi) telegram terminal client untuk sistem Unix. Komunikasi utama server Telegram dilakukan melalui protokol MTProto encryption protocol, yaitu sebuah protokol biner buatan Telegram sendiri. Jadi, ketika hendak menjalankan bot Telegram, bot melakukan komunikas dengan server Telegram melalui MTProto dengan antarmuka HTTP[10].

\section{METODE PENELITIAN}

Penelitian sistem pakar memanfaatkan instant messenger sebagai media konsultasi dini medis ini dilakukan dengan tahapan sebagai berikut.
a. Melakukan studi literatur.
b. Mempelajari dan memahami proses yang terjadi dalam sistem.
c. Pemodelan sistem
d. Membuat sistem.
e. Melakukan pengujian dan analisis hasil pengujian sistem.

f. Membuat hasil dan kesimpulan dari penelitian.

g. Membuat laporan dari proses penelitian.

\subsection{Gambaran Umum Sistem}

Rancangan sistem yang dibuat adalah sebuah sistem Chatbot dalam aplikasi Telegram Messaging yang dapat melakukan diagnosa awal penyakit ginjal. Gambaran umum sistem dapat dilihat pada Gambar 2.

Pada Gambar 2 dapat dilihat bahwa cara kerja dari sistem adalah pengguna menginput data keluhan sesuai pertanyaan yang diajukan sistem (chatbot), kemudian sistem akan mengolah data input-an dengan metode forward chaining menjadi sebuah laporan hasil diagnosa kepada pengguna.

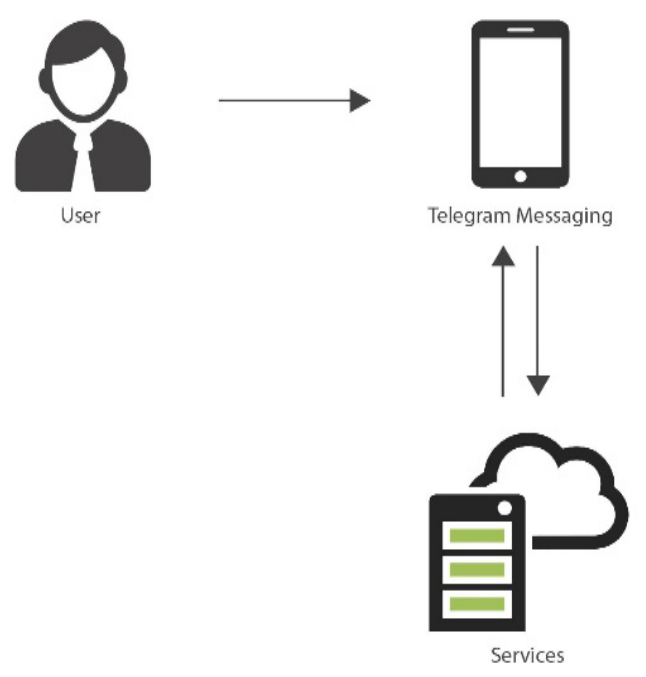

Gambar 2 Gambaran Umum Sistem

\subsection{Data Basis Pengetahuan}

\subsubsection{Rule Fakta Basis Pengetahuan Penyakit Ginjal}

Basis pengetahuan ini didapatkan dari proses wawancara terhadap dua pakar yaitu akademisi dan dokter yang berkompeten di bidang penyakit ginjal. Basis pengetahuan dapat dilihat pada Tabel 1 pengkodean gejala penyakit ginjal, Tabel 2 Tabel pengkodean gejala penyakit ginjal, dan Tabel 3 rule penyakit ginjal.

Tabel 1 Pengkodean Penyakit Ginjal

\begin{tabular}{|c|c|l|}
\hline No. & Kode & \multicolumn{1}{|c|}{ Penyakit } \\
\hline 1 & P1 & Infeksi Saluran Kemih Bagian Atas \\
\hline 2 & P2 & Infeksi Saluran Kemih Bagian Bawah \\
\hline 3 & P3 & Batu Ginjal \\
\hline 4 & P4 & Kanker Ginjal \\
\hline
\end{tabular}




\begin{tabular}{|l|l|l|}
\hline 5 & P5 & Gagal Ginjal Akut \\
\hline 6 & P6 & Gagal Ginjal Kronis \\
\hline 7 & P7 & Sindrom Nefrotik \\
\hline 8 & P8 & Penyakit Ginjal Polikistik \\
\hline
\end{tabular}

Tabel 2 Pengkodean Gejala Penyakit Ginjal

\begin{tabular}{|c|c|c|}
\hline No. & Kode & Gejala Penyakit Ginjal \\
\hline 1 & G1 & Demam tinggi dan menggigil \\
\hline 2 & G2 & $\begin{array}{l}\text { Nyeri pada pinggang sisi belakang } \\
\text { atau samping satu atau kedua sisi }\end{array}$ \\
\hline 3 & G3 & $\begin{array}{l}\text { Nyeri dan rasa terbakar ketika buang } \\
\text { air kecil }\end{array}$ \\
\hline 4 & G4 & Urin berbau busuk, keruh, bernanah \\
\hline 5 & G5 & $\begin{array}{l}\text { Terdapat darah dalam urin/ urin } \\
\text { berwarna kemerahan }\end{array}$ \\
\hline 6 & G6 & Sering buang air kecil \\
\hline 7 & G7 & $\begin{array}{l}\text { Desakan untuk segera buang air } \\
\text { kecil }\end{array}$ \\
\hline 8 & G8 & Mual dan muntah \\
\hline 9 & G9 & Merasa lesu \\
\hline 10 & G10 & Mudah kelelahan \\
\hline 11 & G11 & $\begin{array}{l}\text { Gangguan daya pikir/ merasa } \\
\text { kebingungan }\end{array}$ \\
\hline 12 & G12 & Demam yang menetap \\
\hline 13 & G13 & $\begin{array}{l}\text { Nyeri yang menjalar ke perut bawah } \\
\text { dan selangkangan (hilang timbul) }\end{array}$ \\
\hline 14 & G14 & Jumlah urin yang menurun/sedikit \\
\hline 15 & G15 & $\begin{array}{l}\text { Terdapat benjolan pada punggung } \\
\text { bawah atau pinggang satu atau } \\
\text { kedua sisi }\end{array}$ \\
\hline 16 & G16 & Penurunan nafsu makan \\
\hline 17 & G17 & $\begin{array}{l}\text { Penurunan berat badan tanpa sebab } \\
\text { yang jelas }\end{array}$ \\
\hline 18 & G18 & Tidak keluar urin sama sekali \\
\hline 19 & G19 & $\begin{array}{l}\text { Bengkak pada salah satu atau lebih } \\
\text { (wajah, badan, kaki, tangan) }\end{array}$ \\
\hline 20 & G20 & Sesak napas \\
\hline 21 & G21 & Gatal-gatal pada kulit \\
\hline 22 & G22 & Sakit Kepala \\
\hline 23 & G23 & Peningkatan jumlah urin \\
\hline 24 & G24 & $\begin{array}{l}\text { Warna kulit bertambah gelap tanpa } \\
\text { sebab yang jelas }\end{array}$ \\
\hline 25 & G25 & Urin yang berbuih \\
\hline 26 & G26 & Peningkatan berat badan \\
\hline 27 & $\mathrm{G} 27$ & $\begin{array}{l}\text { Penurunan kesadaran hingga tidak } \\
\text { sadarkan diri }\end{array}$ \\
\hline
\end{tabular}

Tabel 3 Rule Sistem Pakar Penyakit Ginjal

\begin{tabular}{|c|c|c|c|c|c|c|c|c|}
\hline \multirow{2}{*}{ Gejala } & \multicolumn{7}{|c|}{ Penyakit } \\
\hline & P1 & P2 & P3 & P4 & P5 & P6 & P7 & P8 \\
\hline G1 & $\sqrt{ }$ & $\sqrt{ }$ & & & & & & \\
\hline G2 & $\sqrt{ }$ & & $\sqrt{ }$ & $\sqrt{ }$ & & & & $\sqrt{ }$ \\
\hline G3 & $\sqrt{ }$ & $\sqrt{ }$ & $\sqrt{ }$ & & & & & \\
\hline G4 & $\sqrt{ }$ & & $\sqrt{ }$ & & & & & $\sqrt{ }$ \\
\hline G5 & $\sqrt{ }$ & $\sqrt{ }$ & $\sqrt{ }$ & $\sqrt{ }$ & & $\sqrt{ }$ & & $\sqrt{ }$ \\
\hline G6 & $\sqrt{ }$ & $\sqrt{ }$ & $\sqrt{ }$ & & & $\sqrt{ }$ & & $\sqrt{ }$ \\
\hline G7 & $\sqrt{ }$ & $\sqrt{ }$ & & & & & & \\
\hline
\end{tabular}

\begin{tabular}{|c|c|c|c|c|c|c|c|c|}
\hline G8 & $\sqrt{ }$ & & $\sqrt{ }$ & $\sqrt{ }$ & $\sqrt{ }$ & & \\
\hline G9 & $\sqrt{ }$ & & & $\sqrt{ }$ & $\sqrt{ }$ & $\sqrt{ }$ & & $\sqrt{ }$ \\
\hline G10 & $\sqrt{ }$ & & & $\sqrt{ }$ & & $\sqrt{ }$ & & $\sqrt{ }$ \\
\hline G11 & $\sqrt{ }$ & & & & & $\sqrt{ }$ & & $\sqrt{ }$ \\
\hline G12 & & & & $\sqrt{ }$ & & & & \\
\hline G13 & & & $\sqrt{ }$ & & & & & \\
\hline G14 & & & $\sqrt{ }$ & & $\sqrt{ }$ & $\sqrt{ }$ & & $\sqrt{ }$ \\
\hline G15 & & & & $\sqrt{ }$ & & & & $\sqrt{ }$ \\
\hline G16 & & & & $\sqrt{ }$ & & $\sqrt{ }$ & $\sqrt{ }$ & \\
\hline G17 & & & & $\sqrt{ }$ & & $\sqrt{ }$ & & \\
\hline G18 & & & & & $\sqrt{ }$ & & & \\
\hline G19 & & & & & & $\sqrt{ }$ & $\sqrt{ }$ & \\
\hline G20 & & & & & & $\sqrt{ }$ & & \\
\hline G21 & & & & & & $\sqrt{ }$ & & \\
\hline G22 & & & & & & $\sqrt{ }$ & & $\sqrt{ }$ \\
\hline G23 & & & & & & $\sqrt{ }$ & & \\
\hline G24 & & & & & & $\sqrt{ }$ & \\
\hline G25 & & & & & & & $\sqrt{ }$ & \\
\hline
\end{tabular}

\section{HASIL DAN PEMBAHASAN}

Hasil dan pembahasan mengenai tampilan dan hasil pengujani software ini yaitu.

\subsection{Memulai Sistem Bot}

Sebelum menggunakan sistem, pengguna harus memiliki akun login ke dalam aplikasi Telegram terlebih dahulu. Untuk membuat akun, pengguna harus meregistrasi melalui ponsel dan menggunakan nomor teleponnya untuk proses autentifikasi. Setelah proses registrasi berhasil barulah calon pasien dapat melakukan proses diagnosa pada aplikasi Telegram di perangkat yang mendukung. User harus menambahkan akun @PakarGinjalBot dan membuat percakapan dengan meng-klik Start, barulah sistem memulai.

\subsection{Tampilan Pembuka Dan Pertanyaan Biodata}

Setelah sistem bot dimulai, maka bot secara otomatis akan mengirim salam pembuka. Pada bagian awal bot akan menanyakan data diri calon pasien yang nantinya akan menjadi identitas calon pasien yang akan melakukan diagnosa awal. Pertanyaan tersebut berupa nama, umur, usia, dan jenis kelamin seperti ditampilkan pada Gambar 3. 


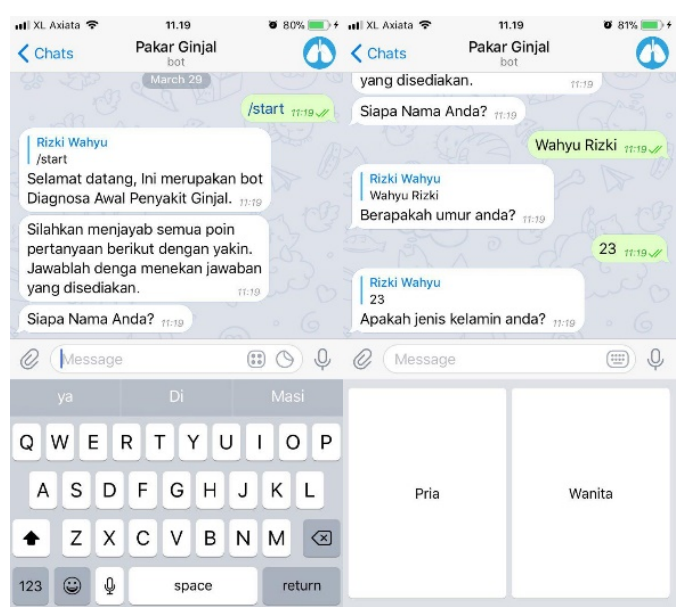

Gambar 3 Tampilan awal pertanyaan biodata oleh bot

\subsection{Tampilan Pertanyaan Gejala}

Setelah pertanyaan data diri selesai dijawab bot akan langsung mengajukan pertanyaan mengenai keluhan yang dirasakan pasien. Dalam keseluruhan pertanyaan diajukan sebanyak 27 poin pertanyaan singkat yang dapat dijawab dengan meng-klik jawaban ya/tidak yang ditampilkan melalui interface inline pada dasar tampilan sistem seperti pada Gambar 4.

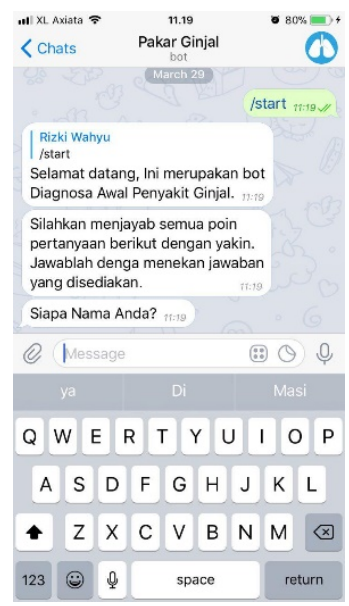

Gambar 4 Tampilan Pertanyaan Diagnosa

\subsection{Tampilan Hasil Diagnosa}

Setelah seluruh pertanyaan selesai diajukan dan terjawab, sistem akan mengirim kesimpulan diagnosa awal kemungkinan penyakit ginjal yang dialami calon pasien melalui chat. Selain itu sistem juga akan mengirimkan salam penutup beserta petunjuk untuk memulai kembali sistem, seperti pada Gambar 5.

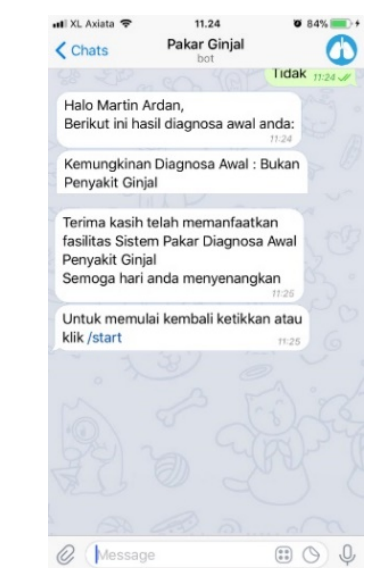

Gambar 5 Hasil diagnosa

\subsection{Pengujian Menggunakan Metode Black Box}

Pengujian black box adalah metode yang mana menguji fungsi-fungsi rancangan sistem, apakah rancangan sistem Bot diagnosa awal penyakit ginjal berbasis Telegram yang dibangun sudah sesuai dengan yang rencana dan dapat berjalan sesuai dengan perintah. Hasil pengujian ini ditunjukkan pada Tabel 4 .

Tabel 4 Tabel pengujian Black Box

\begin{tabular}{|c|c|c|c|c|}
\hline $\begin{array}{l}\text { Nama } \\
\text { Pengujian }\end{array}$ & Butir Uji & $\begin{array}{l}\text { Tindakan } \\
\text { Pengujian }\end{array}$ & $\begin{array}{l}\text { Jenis } \\
\text { Penguji } \\
\text { an }\end{array}$ & $\begin{array}{l}\text { Hasil } \\
\text { Penguji } \\
\text { an }\end{array}$ \\
\hline Mulai & $\begin{array}{l}\text { Memulai } \\
\text { diagnosa }\end{array}$ & $\begin{array}{l}\text { Klik } \\
\text { tombol start }\end{array}$ & Sistem & Berhasil \\
\hline \multirow[b]{2}{*}{ Jawab } & $\begin{array}{l}\text { Jawab } \\
\text { pertanyaan } \\
\text { dengan teks }\end{array}$ & Kirim teks & Sistem & Berhasil \\
\hline & $\begin{array}{l}\text { Jawab } \\
\text { pertanyaan } \\
\text { dengan } \\
\text { GUI }\end{array}$ & Klik pilihan & Sistem & Berhasil \\
\hline $\begin{array}{l}\text { Sistem } \\
\text { Pakar }\end{array}$ & $\begin{array}{l}\text { Hasil } \\
\text { sistem } \\
\text { pakar }\end{array}$ & $\begin{array}{l}\text { Mengakses } \\
\text { hasil sistem } \\
\text { pakar }\end{array}$ & Sistem & Berhasil \\
\hline
\end{tabular}

\subsection{Analisa Usability Scale Software}

Analisa software yang telah dibuat dilakukan dengan menyebarkan kuesioner. Dimana, target responden adalah masyarakat umum, yaitu pengguna akan mencoba untuk menggunakan aplikasi ini.

Skrip kuesioner yang dibuat pada penelitian ini akan menggunakan Sistem Usabilty Scale (SUS). Kuesioner akan diberikan kepada 20 partisipan yang akan mengisi kuisioner dengan 10 poin pertanyaan, antara lain:

a. Saya akan sering menggunakan aplikasi ini. 
b. Saya merasa aplikasi ini terlalu kompleks namun dapat dikembangkan lebih sederhana lagi.

c. Saya merasa aplikas ini cukup sederhana dan mudah digunakan.

d. Berdasarkan pengalaman menggunakan aplikasi ini, saya memerlukan bantuan teknisi untuk menggunakannya.

e. Saya merasa integrasi sistem ini cukup baik.

f. Saya rasa pengembangan aplikasi ini tidak konsisten.

g. Saya rasa kebanyakan pengguna akan belajar menggunakan aplikasi ini cukup mudah dan cepat.

h. Saya merasa aplikasi ini tidak praktis.

i. Saya percaya untuk menggunakan aplikasi ini.

j. Saya harus belajar terlebih dahulu sebelum saya dapat menggunakan aplikasi ini.

Pengujian ini melakukan analisa data dengan cara responden Kuesioner terdiri dari sepuluh soal pilihan ganda dengan seluruh pertanyaan mengacu pada pendapat mereka setelah menggunakan bot sistem diagnosa awal penyakit ginjal berbasis Telegram. Selanjutnya responden akan mengisi skrip kuesioner dan terakhir melakukan analisis dari hasil usability testing untuk rekomendasi perbaikan sistem ke depannya. Data hasil kuesioner yang dilakukan dapat dilihat pada Tabel 5.

Tabel 5 Data hasil survey SUS

\begin{tabular}{|c|c|c|c|c|c|c|c|c|c|c|}
\hline Responden & \multicolumn{7}{|c|}{ PERTANYAN } \\
\cline { 2 - 10 } & 1 & 2 & 3 & 4 & 5 & 6 & 7 & 8 & 9 & 10 \\
\hline 1 & 4 & 2 & 4 & 2 & 4 & 2 & 4 & 2 & 4 & 2 \\
\hline 2 & 4 & 2 & 4 & 2 & 2 & 2 & 5 & 2 & 5 & 2 \\
\hline 3 & 5 & 2 & 4 & 2 & 4 & 2 & 5 & 2 & 4 & 2 \\
\hline 4 & 4 & 1 & 5 & 2 & 4 & 2 & 5 & 2 & 4 & 1 \\
\hline 5 & 4 & 1 & 5 & 2 & 4 & 2 & 5 & 2 & 4 & 1 \\
\hline 6 & 4 & 2 & 4 & 1 & 3 & 2 & 5 & 2 & 4 & 2 \\
\hline 7 & 4 & 2 & 5 & 2 & 4 & 2 & 4 & 2 & 4 & 2 \\
\hline 8 & 4 & 2 & 5 & 2 & 4 & 2 & 5 & 2 & 4 & 2 \\
\hline 9 & 5 & 2 & 5 & 2 & 4 & 1 & 5 & 2 & 4 & 2 \\
\hline 10 & 4 & 2 & 4 & 2 & 3 & 2 & 5 & 2 & 4 & 2 \\
\hline 11 & 3 & 2 & 4 & 2 & 3 & 2 & 4 & 5 & 3 & 2 \\
\hline 12 & 3 & 1 & 5 & 2 & 3 & 1 & 5 & 2 & 3 & 2 \\
\hline 13 & 3 & 2 & 4 & 1 & 3 & 2 & 5 & 2 & 4 & 1 \\
\hline 14 & 4 & 2 & 5 & 1 & 3 & 1 & 5 & 2 & 4 & 2 \\
\hline 15 & 5 & 3 & 4 & 3 & 3 & 2 & 4 & 2 & 3 & 2 \\
\hline 16 & 4 & 2 & 5 & 2 & 4 & 2 & 5 & 1 & 4 & 2 \\
\hline 17 & 4 & 4 & 4 & 5 & 4 & 2 & 4 & 2 & 3 & 5 \\
\hline 18 & 3 & 2 & 5 & 3 & 3 & 2 & 5 & 2 & 3 & 1 \\
\hline 19 & 4 & 3 & 4 & 3 & 4 & 2 & 4 & 4 & 4 & 3 \\
\hline 20 & 4 & 3 & 5 & 3 & 5 & 2 & 4 & 2 & 3 & 2 \\
\hline
\end{tabular}

Untuk nilai pernyataan ganjil akan dikurangi 1 skala nilai yang diberikan responden. Dan untuk pernyataan genap adalah 5 dikurangi dari nilai skala yang diberikan responden. Semua jumlah skala nilai akan dikalikan dengan 2,5 untuk mendapatkan nilai rata-rata sistem usabilty scale (SUS) . Dari hasil konversi data pengujian sistem usabilty scale (SUS), diperoleh skor rata-rata interpretasi sistem usabilty scale (SUS) sebesar 78 yang berarti pengujian berada di di atas rata-rata sehingga dinyatakan dapat diterima (acceptable) dan berjalan dengan baik pada Telegram Messaging.

\section{KESIMPULAN}

Berdasarkan hasil pengujian dan analisis dapat dibuat kesimpulan sebagai berikut:

1. Aplikasi sistem pakar berbasis instant messenger untuk diagnosa awal penyakit ginjal dapat menyelesaikan masalah yaitu dapat menampilkan hasil diagnosa dengan cepat dan tepat berdasarkan pertanyaan gejala-gejala yang diajukan oleh sistem.

2. Aplikasi sistem pakar berbasis instant messenger untuk diagnosa awal penyakit ginjal dapat melakukan percakapan layaknya pakar secara otonom dalam aplikasi Instant Messaging Telegram.

3. Pada pengujian black box, aplikasi sistem pakar diagnosa awal penyakit ginjal memiliki fungsi-fungsi yang telah dinyatakan berhasil dijalankan sesuai dengan fungsinya masing-masing.

4. Berdasarkan hasil survey pengujian sistem usabilty scale (SUS) pada aplikasi sistem pakar diagnosa awal penyakit ginjal, responden memberikan skor ratarata sebesar 78 yang berarti hasil pengujian memiliki nilai di diatas rata-rata. Dengan demikian dapat disimpulkan bahwa aplikasi sistem pakar diagnosa awal penyakit ginjal dapat dinyatakan dapat diterima (acceptable) dan berjalan dengan baik pada Telegram Messaging.

\section{DAFTAR PUSTAKA}

[1] Tim Redaksi VITA HEALTH, 2008. Gagal Ginjal (Informasi Lengkap Untuk Penderita dan Keluarganya). Jakarta: Gramedia Pustaka Utama.

[2] Hartati, S. \& Iswanti, S., 2013. Sistem pakar \& pengembangannya. Yogyakarta: Graha IImu. 
[3] Nur, R., 2016. Rancang Bangun Telegram Bot Pada Telegram Messenger Dengan Metode Log Pulling Untuk Koperasi KOPMA UGM. Yogyakarta: Universitas Gadjah Mada..

[4] Kurniawan, B., 2011. Aplikasi Sistem Pakar Berbasis WEB Untuk Diagnosa Penyakit Gigi Dan Mulut. Jakarta: UIN Syarif Hidayatullah.

[5] Kusuma, W. N., 2011. Perancangan Sistem Pakar Untuk Diagnosis Penyakit Mulut dan Gigi Menggunakan Bahasa Pemrograman Clips. Yogyakarta: Universitas Gajah Mada.

[6] RSUP Dr. M. DJAMIL, 2014. 10 Penyakit Terbanyak Rawat Inap Tahun 2014. [Online] rsdjamil.co.id/pages/10-penyakitterbanyak-rawat-inap-tahun-2014. [Diakses 16 Juni 2017].

[7] Wila, W. I., 2002. Sindrom Nefroktik: Buku ajar Nefrotik. 2 penyunt. Jakarta: Balai Penerbit FKH Ul.

[8] Nita, M. \& Rahmat, H., 2012. Perancangan Sistem Pakar: Studi Kasus Sistem Pakar Kenaikan Jabatan. Yogyakarta: Ghalia Indonesia.

[9] Kusumadewi, S., 2005. Kecerdasan Buatan, Edisi Pertama. Yogyakarta: Graha IImu.

[10]Telegram Messenger LLP, 2015. Bots: An introduction for developers. [Online] Available at: core.telegram.org/bots [Diakses 24 Februari 2018].

[11]Brooke, J., 2011. Measuring Usability With The System Usability Scale (SUS). [Online] Available at: https://measuringu.com/sus/ [Diakses 23 September 2017]. 